\title{
Role of Interfacial Interactions on the Anomalous Swelling of Polymer Thin Films in Supercritical Carbon Dioxide
}

\author{
YUAN LI, ${ }^{1}$ EUN J. PARK, ${ }^{2}$ KWON T. LIM, ${ }^{2}$ KEITH P. JOHNSTON, ${ }^{1,3}$ PETER F. GREEN ${ }^{4}$ \\ ${ }^{1}$ Graduate Program in Materials Science and Engineering, University of Texas at Austin, Austin, Texas 78712 \\ ${ }^{2}$ Division of Image and Information Engineering, Pukyong National University, Pusan 608-739, South Korea \\ ${ }^{3}$ Department of Chemical Engineering, University of Texas at Austin, Austin, Texas 78712 \\ ${ }^{4}$ Department of Materials Science and Engineering, University of Michigan, Ann Arbor, Michigan 48109
}

Received 19 September 2006; revised 6 February 2007; accepted 7 February 2007

DOI: 10.1002 / polb.21159

Published online in Wiley InterScience (www.interscience.wiley.com).

\begin{abstract}
It has recently been shown that thin polymer films in the nanometer thickness range exhibit anomalous swelling maxima in supercritical $\mathrm{CO}_{2}\left(\mathrm{Sc}_{-} \mathrm{Co}_{2}\right)$ in the vicinity of the critical point of $\mathrm{CO}_{2}$. The adsorption isotherm of $\mathrm{CO}_{2}$ on carbon black, silica surfaces, porous zeolites, and other surfaces, is known to exhibit anomalous maxima under similar $\mathrm{CO}_{2}$ conditions. It is believed that because $\mathrm{CO}_{2}$ possesses a low cohesive energy density, there would be an excess amount of $\mathrm{CO}_{2}$ at the surfaces of these materials and hence the $\mathrm{CO}_{2}$ /polymer interface. This might cause excess $\mathrm{CO}_{2}$ in the polymer films near the free surface, and hence the swelling anomaly. In addition, an excess of $\mathrm{CO}_{2}$ would reside at the polymer/substrate and polymer/ $\mathrm{CO}_{2}$ interfaces for entropic reasons. These interfacial effects, as have been suggested, should account for an overall excess of $\mathrm{CO}_{2}$ in a thin polymer film compared to the bulk, and would be responsible for the anomalous swelling. In this study, we use in situ spectroscopic ellipsometry to investigate the role of interfaces on the anomalous swelling of polymer thin films of varying initial thicknesses, $h_{0}$, exposed to Sc$\mathrm{CO}_{2}$. We examined three homopolymers, poly(1,1'-dihydroperflurooctyl methacrylate) (PFOMA), polystyrene (PS), poly(ethylene oxide) (PEO), that exhibit very different interactions with $\mathrm{Sc}-\mathrm{CO}_{2}$, and the diblock copolymer of PS- $b$-PFOMA. We show that the anomalous swelling cannot be solely explained by the excess adsorption of $\mathrm{CO}_{2}$ at interfaces. @ 2007 Wiley Periodicals, Inc. J Polym Sci Part B: Polym Phys 45: 1313-1324, 2007

Keywords: diblock copolymer; interfaces; supercritical $\mathrm{CO}_{2}$; swelling; thin films
\end{abstract}

\section{INTRODUCTION}

Extensive attention has been paid to the use of supercritical $\mathrm{CO}_{2}\left(\mathrm{Sc}-\mathrm{CO}_{2}\right)$ as an alternative to water or organic solvents in many polymer pro-

This article contains supplementary material available via the Internet at http://www.interscience.wiley.com/jpages/ 0887-6266/suppmat. edu)

Correspondence to: P.F. Green (E-mail: pfgreen@umich.

Journal of Polymer Science: Part B: Polymer Physics, Vol. 45, 1313-1324 (2007) (ㅇ) 2007 Wiley Periodicals, Inc. cesses. $^{1-4}$ In addition to the environmentally benign character of $\mathrm{CO}_{2}$, the tunable property of this supercritical fluid, through varying the pressure or temperature, enables control of its properties as a solvent. Recently, several studies of block copolymer thin films used $\mathrm{CO}_{2}$ to induce the ordering of copolymer templates, ${ }^{5-8}$ to control the spatial distribution of metal nanoparticles in copolymer matrices, ${ }^{9}$ and to diffuse precursors in copolymers for the synthesis of nanoporous materials. ${ }^{10}$ In addition to polymer processing, supercritical $\mathrm{CO}_{2}$ has been investigated as a 
potential medium in many microelectronic thin film processes. ${ }^{11-18}$ For example, it has been shown that $\mathrm{CO}_{2}$ promotes penetration and removal of aqueous surfactant cleaning solutions in methylsilsesquioxane (MSQ) low dielectric constant $(k)$ films. ${ }^{15}$ Moreover, the cleaning and drying steps may be integrated with silylation in $\mathrm{CO}_{2}$ to convert the hydrophilic surface after etching and ashing to a hydrophobic surface to restore the $k$-value. ${ }^{15}$

In this article, we are particularly interested in $\mathrm{Sc}-\mathrm{CO}_{2}$ processing of polymer thin films. Polymer thin films exhibit film thickness dependent properties. Properties that include the glass transition temperatures, wetting, and phase equilibrium are of scientific and technological interests for a range of thin film based technologies, from microelectronics to sensors. There have been a few investigations on the effects of $\mathrm{Sc}-\mathrm{CO}_{2}$ on the properties of thin polymer. ${ }^{5-8,19-25}$ Pham et al. found a Sc- $\mathrm{CO}_{2}$ induced devitrification transition in polymethyl methacrylate (PMMA) and polystyrene (PS) thin films. ${ }^{21,22}$ Meli et al. showed that the kinetics of the morphological destabilization of PS thin films in $\mathrm{Sc}-\mathrm{CO}_{2}$ are suppressed. $^{20}$ Studies have also shown that the order-disorder transition (ODT) temperature of $\mathrm{A}-b$-B diblock copolymer films in $\mathrm{Sc}-\mathrm{CO}_{2}$ are increased appreciably compared to the case in vacuum; on the other hand, for bulk copolymers, the effect is opposite. $5,7,8$

With regard to the behavior of $\mathrm{CO}_{2}$ in the vicinity of its critical point, an anomalous maximum is known to occur, which was first observed in the adsorption isotherm of $\mathrm{CO}_{2}$ on carbon black ${ }^{26}$ and on silica surfaces. ${ }^{27,28}$ Similar observations were made for other adsorbents, ${ }^{29-32}$ including porous Zeolite, ${ }^{31}$ and activated carbon. ${ }^{29,32}$ Anomalous adsorption has been rationalized by the fact that long-range density fluctuations of $\mathrm{CO}_{2}$, affects the Gibbs excess adsorption of $\mathrm{CO}_{2}$ under critical conditions. ${ }^{33}$ The swelling of polymer thin films in $\mathrm{CO}_{2}$ also exhibits anomalous maximum in the vicinity of the critical point. ${ }^{25,34-39}$ Specifically, Sirard et al. first discovered the anomalous maxima in the swelling isotherms of PMMA thin films in $\mathrm{CO}_{2}$ by in situ spectroscopic ellipsometry. ${ }^{25}$ Koga et al. used neutron reflectivity to explore the anomalous swelling of polymer thin films with thickness $h$ less than $10 R_{\mathrm{g}}$ in Sc$\mathrm{CO}_{2} \cdot{ }^{34-36,38,39}$ The effect of $\mathrm{CO}_{2}$ on the welding kinetics of colloidal crystals of PS was examined by in situ measurement of Bragg diffraction and by scanning electron microscopy. ${ }^{40}$ An anomalous excess in the welding rate was observed in the region where $\mathrm{CO}_{2}$ is highly compressible. ${ }^{40}$ It has been suggested that interfacial effects are primarily responsible for the anomalous swelling exhibited by thin polymer films. This follows from the fact that there exists an excess of $\mathrm{CO}_{2}$ in thin polymer films compared to the bulk. This occurs for two reasons: (1) there is an excess of $\mathrm{CO}_{2}$ at the polymer/substrate interface as well as at the $\mathrm{CO}_{2}$ /polymer interfacial region due to entropic reasons; (2) the low cohesive energy density of $\mathrm{CO}_{2}$ would account for excess $\mathrm{CO}_{2}$ in the interfacial region of the polymer at the $\mathrm{CO}_{2}$ /polymer interface. While additional studies have shed further insight into thin film swelling in $\mathrm{CO}_{2},{ }^{37}$ the role of interfaces on the anomalous maximum remains unclear.

In this article, we examine the role of interfaces and polymer- $\mathrm{CO}_{2}$ interactions on the swelling of a variety of polymer thin films exposed in Sc- $\mathrm{CO}_{2}$. We examine a highly $\mathrm{CO}_{2}$-philic polymer, poly $\left(1,1^{\prime}\right.$-dihydroperflurooctyl methacrylate) (PDHFOMA, also abbreviated as PFOMA) in addition to other polymer systems: PS, poly(ethylene oxide) (PEO), and the diblock copolymer of polystyrene- $b$-poly $\left(1,1^{\prime}, 2,2^{\prime}\right.$-tetrahydroperflurooctyl methacrylate) (PS- $b$-PTHFOMA). We are interested in a larger thickness regime $(100-300 \mathrm{~nm})$ than the previously examined thickness range (below $50 \mathrm{~nm}$ ). ${ }^{34,35}$ We show that the thickness of the swollen film exhibits a linear dependence on the initial film thickness, regardless of the polymer. The magnitude of the dependence (slope) increases with increasing $\mathrm{CO}_{2}$-philicity of the polymer.

\section{EXPERIMENTAL}

\section{Materials}

Three homopolymers, poly(1,1'-dihydroperflurooctyl methacrylate) (PDHFOMA, or abbreviated as PFOMA), polystyrene (PS) and poly(ethylene oxide) (PEO), and the diblock copolymer of polystyrene- $b$-poly $\left(1,1^{\prime}, 2,2^{\prime}\right.$-tetrahydroperflurooctyl methacrylate) (PS-b-PTHFOMA) are studied in this work. Their molecular weights, dissolving solvents and sources are listed in Table $1 .^{6,41}$ Thin films were prepared by dissolving each polymer in its corresponding solvent (polymer concentration about 1-2 wt \%) and then spin-casting the solution onto silicon wafers with a native oxide layer (Wafer World). Different thicknesses (100- 
Table 1. Molecular Weights and Sources of Polymers

\begin{tabular}{|c|c|c|c|}
\hline Polymer & $\begin{array}{l}\text { Molecular Weight } \\
\quad(\mathrm{kg} / \mathrm{mole})\end{array}$ & Casting Solvent & Source \\
\hline PDHFOMA & 100 & $\begin{array}{l}\text { 1,1,2-Trichlorotrifluroethane } \\
\text { (Freon-113) }\end{array}$ & $\begin{array}{l}\text { Synthesized by Dr. Lim, } \\
\text { see ref. } 41\end{array}$ \\
\hline PS- $b$-PTHFOMA & $27 / 127$ & $\begin{array}{l}\text { Co-solvent mixture of Freon-113 } \\
\quad(\sim 80 \text { wt } \%) \text { and toluene }(\sim 20 \text { wt } \%)\end{array}$ & $\begin{array}{l}\text { Synthesized by Dr. Lim, } \\
\text { see ref. } 6\end{array}$ \\
\hline PS & 30 & Toluene & $\begin{array}{l}\text { Purchased from Pressure } \\
\text { Chemical }\end{array}$ \\
\hline PEO & 8.6 & Chloroform & $\begin{array}{l}\text { Purchased from Polymer } \\
\text { Source }\end{array}$ \\
\hline
\end{tabular}

$300 \mathrm{~nm}$ ) were obtained by controlling the spin rate and concentration of polymer solutions. Prior to swelling experiments, PS and PS- $b$ PTHFOMA films were annealed in vacuum ovens at $120{ }^{\circ} \mathrm{C}$ for $3 \mathrm{~h}$ while PEO and PFOMA films were annealed in vacuum ovens at $70{ }^{\circ} \mathrm{C}$ for $3 \mathrm{~h}$ to remove any residue solvent.

\section{In Situ Swelling Experiments}

Spectroscopic ellipsometry (J. A. Wollam Co.) and a customer-built high pressure cell were used to measure in situ swelling of polymer films in supercritical $\mathrm{CO}_{2}\left(\mathrm{Sc}-\mathrm{CO}_{2}\right)$. The design of the cell and the experimental setup had been described elsewhere. ${ }^{23}$ The ellipsometry angle of incidence of $70^{\circ}$ was used for all samples. $\mathrm{CO}_{2}$ pressure was controlled by a strain gauge pressure transducer (Sensotec). The cell was heated using four cartridge heaters (Omega) that were inserted at the top and a PID temperature controller (Omega) was used to control temperature within an accuracy of $\pm 0.2{ }^{\circ} \mathrm{C}$.

The experimental procedure can be described as the following. Once a sample was loaded into the high pressure cell and subsequently sealed, at least $1 \mathrm{~h}$ was allowed for thermal equilibration at the desired experimental temperatures $\left(35\right.$ or $50{ }^{\circ} \mathrm{C}$ ). Then $\mathrm{CO}_{2}$ (Air Products, >99.999\%) was charged into the cell using a manual pressure generator (High-Pressure Equipment Co.). At each pressure point, 5-10 min was allowed for the swollen films to reach equilibrium, and then ellipsometry angles $\psi$ and $\Delta$ were measured.

A four-layer model (from top to bottom, a bulk $\mathrm{CO}_{2}$ ambient layer, a swollen polymer layer, a native silicon oxide layer, and a silicon substrate layer) was used to fit the swelling data. Detailed fitting procedures can be found elsewhere. ${ }^{23}$

Journal of Polymer Science: Part B: Polymer Physics DOI 10.1002/polb
The swelling percentage was determined by the following equation assuming uniaxial swelling

$$
S(\%)=\frac{\Delta V}{V_{0}}(\%)=\frac{h-h_{0}}{h_{0}} \times 100 \% \text {. }
$$

Here $V_{0}$ is the initial volume of the film, $h$ is the thickness of the swollen film, and $h_{0}$ is the initial thickness of the polymer film determined by spectroscopic ellipsometry at 0 psig.

\section{Ellipsometry Fitting}

It is well known that the results of spectroscopic ellipsometry can be model dependent. Therefore a model that closely describes the composition of a film is crucial to assure the accuracy of measured thickness and optical constant. ${ }^{42}$ Previous attempts have been made to model an adsorbed $\mathrm{CO}_{2}$ layer between the swollen polymer layer and the $\mathrm{CO}_{2}$ environment. ${ }^{21,25}$ However, this model of a $\mathrm{CO}_{2}$ absorbed layer proved to be unreliable, producing correlations in the fitting parameters and destroyed the uniqueness of the fitting results. ${ }^{21,25}$ In the case of soft materials interfaces, such a layer is extremely thin compared to the film, and is not measurable with ellipsometry. This effect would be apparent in very thin films where the overall percent swelling is large. ${ }^{21,25}$

Data from all of the swelling measurements and the corresponding mean squared error (MSE) values are presented in tabular form in the section for "Supporting Information."

\section{RESULTS}

The results of experiments performed at $35{ }^{\circ} \mathrm{C}$ are first discussed. The swelling experiments were conducted by performing alternating pres- 


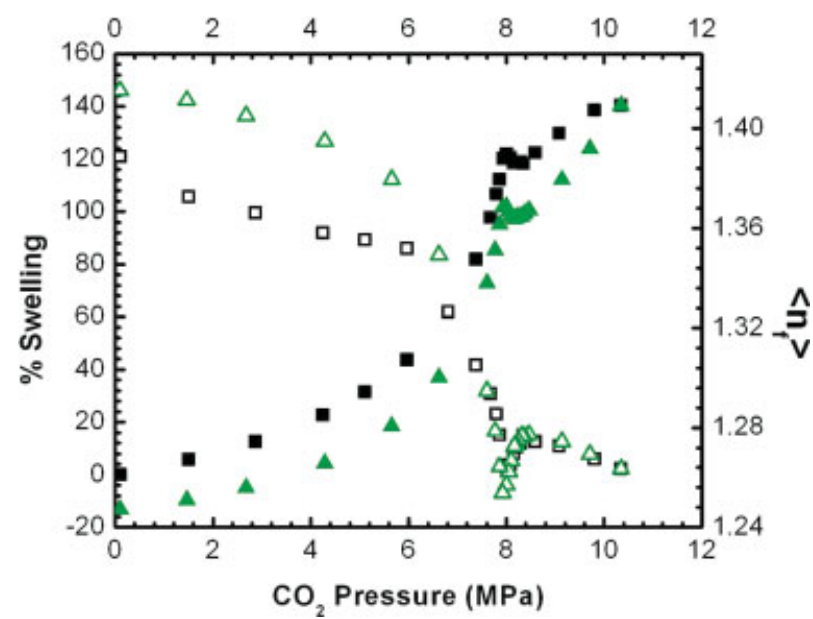

Figure 1. Representative swelling isotherm and the change in average refractive indices at $35{ }^{\circ} \mathrm{C}$ for an $h_{0}=109$ nm PFOMA film. Filled symbols (ם, $\left.\mathbf{\Delta}\right)$ represent \% swelling and open symbols $(\square, \triangle)$ represent the change in average refractive indices. Squares $(\square, \square)$ represent data obtained during the pressurization run and triangles $(\boldsymbol{\Lambda}, \triangle)$ represent data obtained during the depressurization run. [Color figure can be viewed in the online issue, which is available at www. interscience.wiley.com.]

surization/depressurization runs, where both film thickness and average reflective index of the $\mathrm{CO}_{2}$-swollen film were recorded..$^{23,25}$ Figure 1 shows a representative isotherm as well as the changes in average refractive indices at $35{ }^{\circ} \mathrm{C}$ for an $h_{0}=109 \mathrm{~nm}$ PFOMA film. Several observations may be made. First, the swelling isotherm exhibits an anomalous maximum, which also corresponds to a sharp minimum in the refractive index curves. The pressure at which this anomalous swelling shows, $8.0 \mathrm{MPa}$, is in excellent agreement with the location of the maximum in the compressibility of $\mathrm{CO}_{2}$, that is, density fluctuation, $(\partial \rho / \partial P)_{\mathrm{r}}$, at $35{ }^{\circ} \mathrm{C}{ }^{25,34,35}$ Secondly, the swelling isotherms for PFOMA at low pressures possess positive curvature (concaved up), suggesting that PFOMA films reside in a rubbery state. ${ }^{23,25}$ Because the glass transition temperature of bulk PFOMA is $50{ }^{\circ} \mathrm{C}$ at ambient conditions, ${ }^{6}$ and can be highly depressed in $\mathrm{Sc}-\mathrm{CO}_{2}$, it is not surprising that PFOMA films are rubbery at $35{ }^{\circ} \mathrm{C}$ in $\mathrm{CO}_{2}$. Thirdly, hysteresis between sorption and desorption runs was observed in both the swelling isotherm and the change in average reflective index. Hysteresis is often due to the nonequilibrium state of the initial sorption run for glassy polymers. ${ }^{25}$ However, since PFOMA is believed to be in rubbery state, this discrepancy between sorption and desorption is more likely to be the result of PFOMA dissolution in $\mathrm{CO}_{2}$. Dissolution rates of fluorinated polymer films in $\mathrm{CO}_{2}$ are found to decrease significantly with decreasing films thicknesses. ${ }^{43}$ This might be due to the more dominant role of the polymer/substrate interaction. ${ }^{43}$ Although some dissolution is expected and evident in PFOMA films with thickness below $300 \mathrm{~nm}$, its effect on the sorption isotherms is not obvious. Multiple swelling experiments of PFOMA films shows consistent results at 35 and $50{ }^{\circ} \mathrm{C}$. (These results will be shown next). The influence of dissolution will not be discussed in this article.

Figure 2(a) shows the swelling isotherms for four PFOMA films with various thicknesses at $35^{\circ} \mathrm{C}$. The four isotherms for these films of different thicknesses are consistent. At low pressures, the percent swelling increases slightly with decreasing film thickness. This small swelling enhancement for thinner films in $\mathrm{Sc}-\mathrm{CO}_{2}$ is reasonable because strong enhancement in swelling of polymer thin films was only found when the thickness of film is below $10 R_{\mathrm{g}}\left(h_{0}<10 R_{\mathrm{g}}\right)$. $^{35}$ On the other hand, the influence of film thickness on the anomalous swelling maximum is distinct. From Figure 2 (a), it is evident that the two thinner films have smaller swelling maxima $\left(S_{\max }\right)$ than the two thicker ones. The biggest $S_{\max }$ was observed for the $h_{0}=179 \mathrm{~nm}$ film.

To place the results for the anomalous swelling maxima in perspective, a baseline can be constructed by interpolating the data on either side of the anomalous maxima as shown by the solid lines in Figure 2(b,c). ${ }^{25}$ An effective excess swelling thickness $\left(h_{\text {exc }}\right)$ at the maxima can be defined by

$$
h_{\text {exc }}=h_{0} \times\left(S_{\max }-S_{\text {base }}\right) .
$$

Here $S_{\text {base }}$ is the interpolated swelling percentage from the baseline at the pressure where $S_{\max }$ is observed. Table 2 lists the values of $S_{\max }$, $h_{\text {exc }}$ and the proportional excess swelling, $\Delta_{\text {exc }}$ for each sample. It is clear that $h_{\text {exc }}$ increases as increasing film thickness, consistent with the results of Sirard et al. on the swelling PMMA films in $\mathrm{Sc}-\mathrm{CO}_{2} \cdot{ }^{25}$

It is noteworthy that Koga et al. used the absolute values of $S_{\max }$ to examine the effect of film thickness on anomalous swelling. ${ }^{34,35}$ They found that $S_{\max }$ decreases as increasing film

Journal of Polymer Science: Part B: Polymer Physics DOI 10.1002/polb 

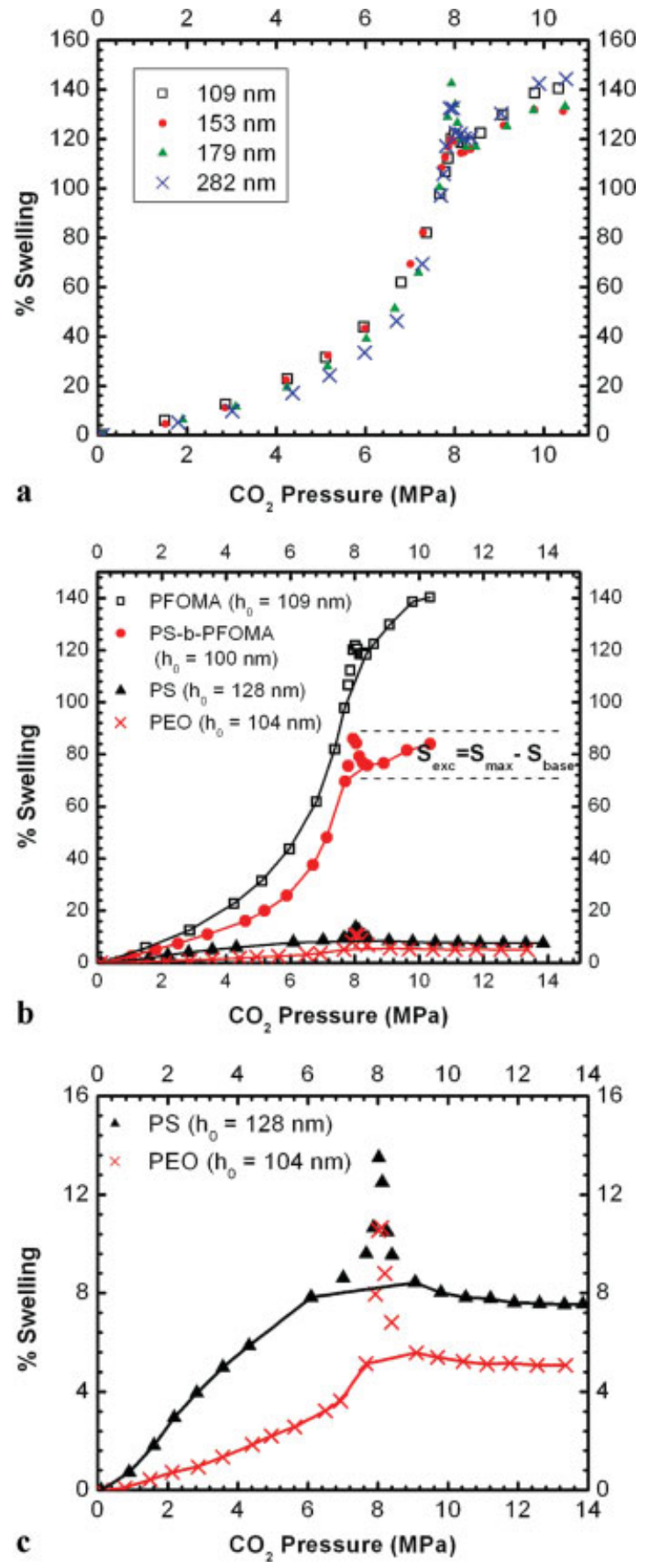

Figure 2. (a) Swelling isotherms for PFOMA films with various thicknesses at $35{ }^{\circ} \mathrm{C}$. (b) Swelling isotherms at $35{ }^{\circ} \mathrm{C}$ for various polymer films with thickness around $100 \mathrm{~nm}$. The solid line in each isotherm represents the interpolated baseline, which is used to estimate the excess \% swelling at the anomalous peak. (c) Swelling isotherms of PS and PEO films with magnified normal axis. [Color figure can be viewed in the online issue, which is available at www.interscience.wiley.com.]

Journal of Polymer Science: Part B: Polymer Physics DOI 10.1002/polb thickness and levels off when $h_{0}$ approaches $8 R_{\mathrm{g}}{ }^{34,35}$ Here, we focus on a much thicker regime, and we examine both $S_{\max }$ and $h_{\mathrm{exc}}$ with different film thicknesses. Because $h_{\text {exc }}$ is strongly depended on the initial film thickness $\left(h_{\text {exc }}=h_{0} \times\left(S_{\max }-S_{\text {base }}\right)\right)$, as film thickness increases ( $h_{0}$ increases), even if $S_{\max }$ decreases (as shown by Koga et al. ${ }^{34,35}$ ), $h_{\text {exc }}$ would still increase (as Table 2 shows).

To examine the effect of polymer-substrate and polymer- $\mathrm{CO}_{2}$ interactions on anomalous swelling maxima, we studied two other homopolymers, PS and PEO as well as the diblock copolymer of PS- $b$-PTHFOMA. Figure 2(b) compares the swelling isotherm for all four polymers at $35{ }^{\circ} \mathrm{C}$, from which $h_{\text {exc }}$ and $\Delta_{\text {exc }}$ are estimated and listed in Table 2. All four isotherms show the characteristic sigmoidal shape as seen in other polymer- $\mathrm{CO}_{2}$ systems. ${ }^{44}$ As expected, the isotherm for the diblock PS- $b$-PTHFOMA lies in between those of PS and PFOMA. The curvatures of the swelling isotherms for PFOMA and PS- $b$-PTHFOMA at low pressure values are positive (concaved up), indicating that both films reside in the rubbery state. On the other hand, the swelling isotherm for PS [Fig. 2(c)] at low pressure values are slightly negative (concaved down), which is consistent with the fact that the plasticization pressure $\left(P_{\mathrm{g}}\right)$ at $35{ }^{\circ} \mathrm{C}$ for $h_{0}$ $=90 \mathrm{~nm}$ PS was found to be $5.2 \mathrm{MPa}^{20,21}$ However, with regard to $\mathrm{PEO}$, another dimension of complexity needs to be considered and will be discussed next.

It is well known that PEO is a crystalline polymer and the crystallization of PEO or copolymers with PEO as a constituent has been widely studied. ${ }^{45-48} \mathrm{Sc}-\mathrm{CO}_{2}$ can depress the glass transition temperature of glassy polymers significantly; similarly, it has been found that both the crystallization temperature $\left(T_{\text {cr }}\right)$ and the melting temperature $\left(T_{\mathrm{m}}\right)$ of crystalline polymers decrease with increasing $\mathrm{CO}_{2}$ pressure. ${ }^{48-50}$ Recently, Madsen employed NMR spectroscopy to study bulk PEO exposed to Sc- $\mathrm{CO}_{2}$ and found $T_{\mathrm{m}}$ (PEO) is depressed from $63{ }^{\circ} \mathrm{C}$ at atmospheric pressure to $43{ }^{\circ} \mathrm{C}$ at $\mathrm{Sc}-\mathrm{CO}_{2}, 8.1 \mathrm{MPa} .{ }^{48}$ The coupling between crystallization and sorption had also been explored, and it was found that the extent of crystallization can affect $\mathrm{Sc}-\mathrm{CO}_{2}$ sorption by reducing both the equilibrium solubility and the diffusivity of $\mathrm{Sc}-\mathrm{CO}_{2}$ in the polymer. ${ }^{49}$

In our study, the PEO films remain in a partially crystalline state throughout the entire pressure range, leading to an extremely small 
Table 2. Analysis of Anomalous Swelling Maximum for Various Polymer Films at $35{ }^{\circ} \mathrm{C}$

\begin{tabular}{|c|c|c|c|c|c|c|}
\hline Polymer & $\begin{array}{c}\text { Initial Film } \\
\text { Thickness } \\
h(\mathrm{~nm})\end{array}$ & $\begin{array}{c}\text { Pressure at } \\
\text { Max. Swelling } \\
(\mathrm{MPa})\end{array}$ & $\begin{array}{c}\text { Max. } \% \\
\text { Swelling } \\
S_{\max }\end{array}$ & $\begin{array}{c}\text { Max. Excess } \% \\
\text { Swelling } \\
S_{\text {exc }}^{a}\end{array}$ & $\begin{array}{l}\text { Max. Excess } \\
\text { Thickness } \\
h_{\text {exc }} \quad(\mathrm{nm})\end{array}$ & $\begin{array}{c}\text { Proportional } \\
\text { Max. Swelling } \\
\Delta_{\text {exc }}\end{array}$ \\
\hline \multirow[t]{4}{*}{ PDHFOMA } & 109 & 8.0 & 122 & 14 & 15 & 0.11 \\
\hline & 153 & 7.9 & 120 & 18 & 28 & 0.15 \\
\hline & 179 & 7.9 & 143 & 37 & 65 & 0.26 \\
\hline & 282 & 7.9 & 133 & 28 & 80 & 0.21 \\
\hline PS- $b$-PTHFOMA & 100 & 8.0 & 86.0 & 14 & 14 & 0.17 \\
\hline PS & 128 & 7.9 & 13.5 & 5.0 & 6.4 & 0.37 \\
\hline $\mathrm{PEO}$ & 104 & 8.1 & 10.7 & 5.4 & 5.6 & 0.51 \\
\hline \multirow[t]{2}{*}{$\mathrm{PMMA}^{25}$} & 88 & 8.0 & 23 & 3 & 2.5 & 0.13 \\
\hline & 321 & 8.0 & 25 & 5 & 16 & 0.2 \\
\hline
\end{tabular}

\footnotetext{
${ }^{\mathrm{a}} S_{\mathrm{exc}}=S_{\max }-S_{\mathrm{base}}$

${ }^{\mathrm{b}} h_{\mathrm{exc}}=h_{0} \times S_{\mathrm{exc}}$

c $\Delta_{\mathrm{exc}}=S_{\mathrm{exc}} / S_{\max }$
}

degree of sorption. For example, as shown in Figure 2(c), at the highest pressure, 13.8 MPa, PEO film swells $5 \%$ at $35{ }^{\circ} \mathrm{C}$. Interestingly, Weidner et al. reported that the solubility of $\mathrm{CO}_{2}$ in amorphous PEO $(4 \mathrm{~kg} / \mathrm{mol})$ is as high as 22 wt $\%$ at $55{ }^{\circ} \mathrm{C}$ and $15 \mathrm{MPa}^{51}$ Because the degree of $\mathrm{CO}_{2}$ swelling in most polymers increases with decreasing temperature ${ }^{52}$ the small degree of swelling reported in our study is the result of crystalline PEO films. Further evidence showing $T_{\mathrm{m}}$ (PEO) is above $35{ }^{\circ} \mathrm{C}$ at $13.8 \mathrm{MPa}$ is that the swelling isotherm levels off at high pressures $(P>10 \mathrm{MPa})$ in the absence of a distinct change in slope; this indicates the absence of a phase transformation at high pressures. Despite of the crystalline state of our PEO films and the associated unusually small degree of swelling, our key finding is, nevertheless, that anomalous swelling maximum is evident in crystalline polymer films.

Table 2 summarizes the results of the anomalous swelling maximum experiments for all polymer films; for comparison, the results by Sirard et al. on PMMA ${ }^{25}$ are included as well. It is clear that the pressure at which anomalous swelling maxima are observed for all films resides in the pressure regime of 7.9-8.1 $\mathrm{MPa}$. Among the polymer films with $h_{0} \sim 100 \pm 10 \mathrm{~nm}$ (for PS film, $h_{0}=128 \mathrm{~nm}$ ) examined in this article, the trend for both the absolute degree of swelling $\left(S_{\max }\right)$ and for the effective excess swelling thickness $\left(h_{\text {exc }}\right)$ in $\mathrm{CO}_{2}$ is PFOMA > PS- $b$ PTHFOMA > PS PEO. However, if we consider Sirard's data on PMMA, ${ }^{25}$ then PMMA swelling percentage is between those for PS and
PS- $b$-PTHFOMA, while it possesses the smallest $h_{\text {exc }}$ of all polymers. Consistently, Koga et al. also found that PMMA has an enormously smaller anomalous swelling maximum than PS and $\mathrm{PB}$, while PMMA swells the most among the three at other pressures. ${ }^{34,35}$ It is also instructive to compare the proportional excess swelling at the anomalous maximum, $\Delta_{\text {exc }}$, for different polymers in Table 2. It is evident that the trend for $\Delta_{\text {exc }}$ is PFOMA $<$ PS- $b$-PTHFOMA $<$ PS $<$ PEO, just opposite to that of $S_{\max }$ and $h_{\text {exc }}$. All these results will be discussed in detail later.

The results obtained at $50{ }^{\circ} \mathrm{C}$ are now discussed. Figure 3 shows the swelling isotherm for three PFOMA films, of different thicknesses, at $50{ }^{\circ} \mathrm{C}$. The shapes of the isotherms are relatively independent of film thickness. The anomalous maxima are suppressed at this temperature, compared to those at $35{ }^{\circ} \mathrm{C}$, but they do exist. They occur at a higher pressure than at $35{ }^{\circ} \mathrm{C}$ and extends over a broader range of pressure; this was identified in an earlier publication. ${ }^{25}$ The swelling isotherms of PFOMA films at 35 and $50{ }^{\circ} \mathrm{C}$ are plotted versus $\mathrm{CO}_{2}$ activity in Figure 4(a). The swelling versus activity curves of all seven isotherms representing the PFOMA films superpose into a single curve. These data further indicate that the PFOMA films reside in the rubbery state at both temperatures. Additional swelling versus $\mathrm{CO}_{2}$ activity plots for PS- $b$-PTHFOMA and PS films are shown in Figure 4(b,c), respectively. In the case of PS [Fig. 4(c)], at lower activities, a small discrepancy between the two isotherms is apparent.

Journal of Polymer Science: Part B: Polymer Physics DOI 10.1002/polb 


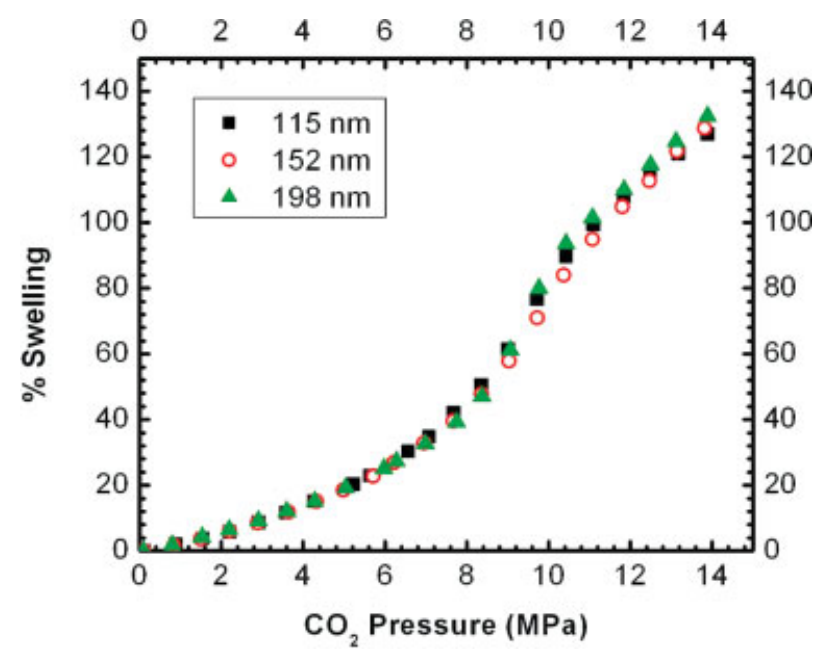

Figure 3. Swelling isotherms for PFOMA films with various thicknesses at $50{ }^{\circ} \mathrm{C}$. [Color figure can be viewed in the online issue, which is available at www.interscience.wiley.com.]

This is because PS undergoes a glassy state to a rubbery state transition. The anomalous swelling maxima are clear for PS films at both temperatures.

The swelling isotherms of PS thin film are compared with those of bulk PS from other groups in Figure 5(a,b). ${ }^{44,53}$ It is evident that below the anomalous maximum, PS films with thickness $h_{0} \sim 130 \mathrm{~nm}$ swell $\sim 1 \%$ more than the bulk analogues. While this slight swelling enhancement in PS films compared with bulk is consistent with the data from Koga et al. ${ }^{35}$ and Sirard et al. ${ }^{23}$ at lower pressures, the difference between bulk and thin films is significant in the vicinity of the critical point.

\section{DISCUSSION}

The role of interfaces on the anomalous swelling of polymer thin films remains an open question, and there is not much agreement among different groups. ${ }^{25,37,54-56}$ Some attribute the anomalous swelling to the surface excess adsorption of $\mathrm{CO}_{2}$,

$$
\Gamma_{\mathrm{ex}}=\int_{0}^{\infty}\left(\rho(z)-\rho_{\mathrm{bulk}}\right) d z .
$$

We briefly alluded to this in the experimental section. In this equation, $z$ is the distance from the substrate $(z=0$ represents the substrate DOI 10.1002/polb
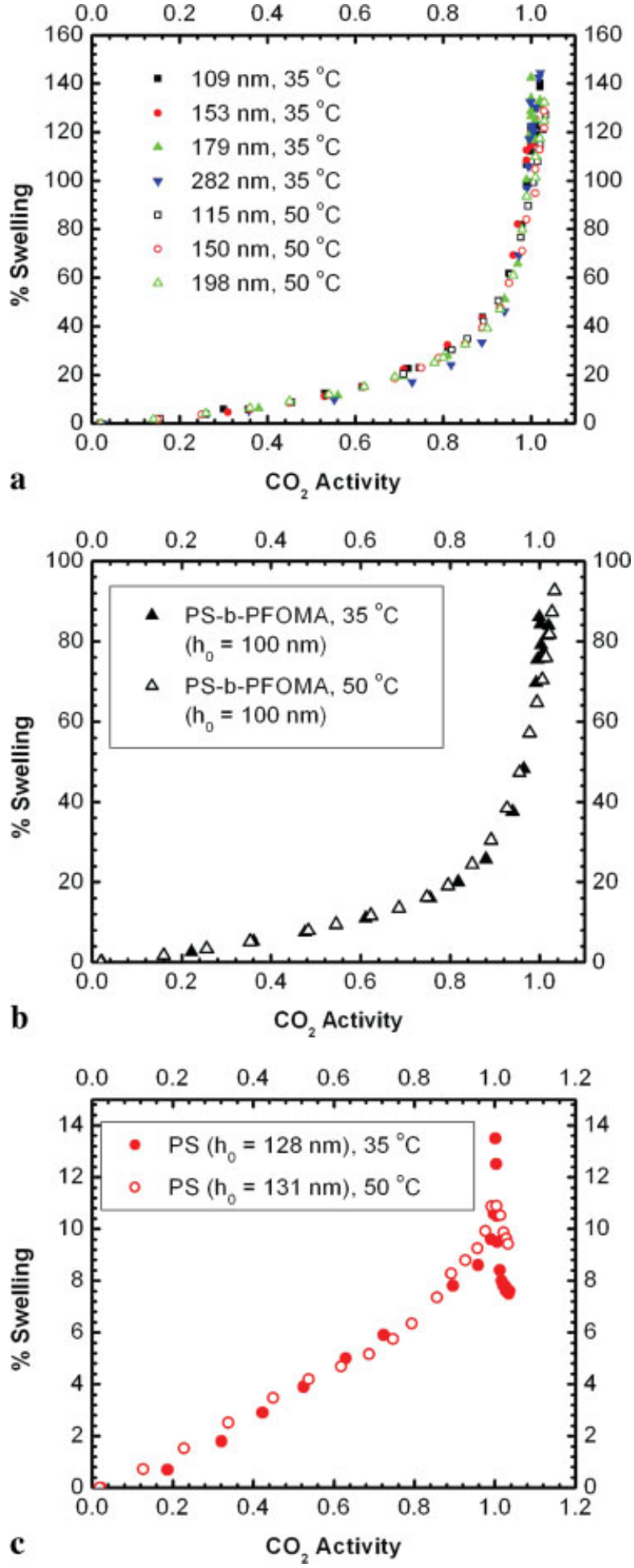

Figure 4. (a) Swelling of PFOMA films with various thicknesses at both $35{ }^{\circ} \mathrm{C}$ and $50{ }^{\circ} \mathrm{C}$ plotted against $\mathrm{CO}_{2}$ activity. (b) Swelling of PS- $b$-PFOMA films plotted against $\mathrm{CO}_{2}$ activity. (c) Swelling of PS films plotted against $\mathrm{CO}_{2}$ activity. [Color figure can be viewed in the online issue, which is available at www.interscience. wiley.com.] 

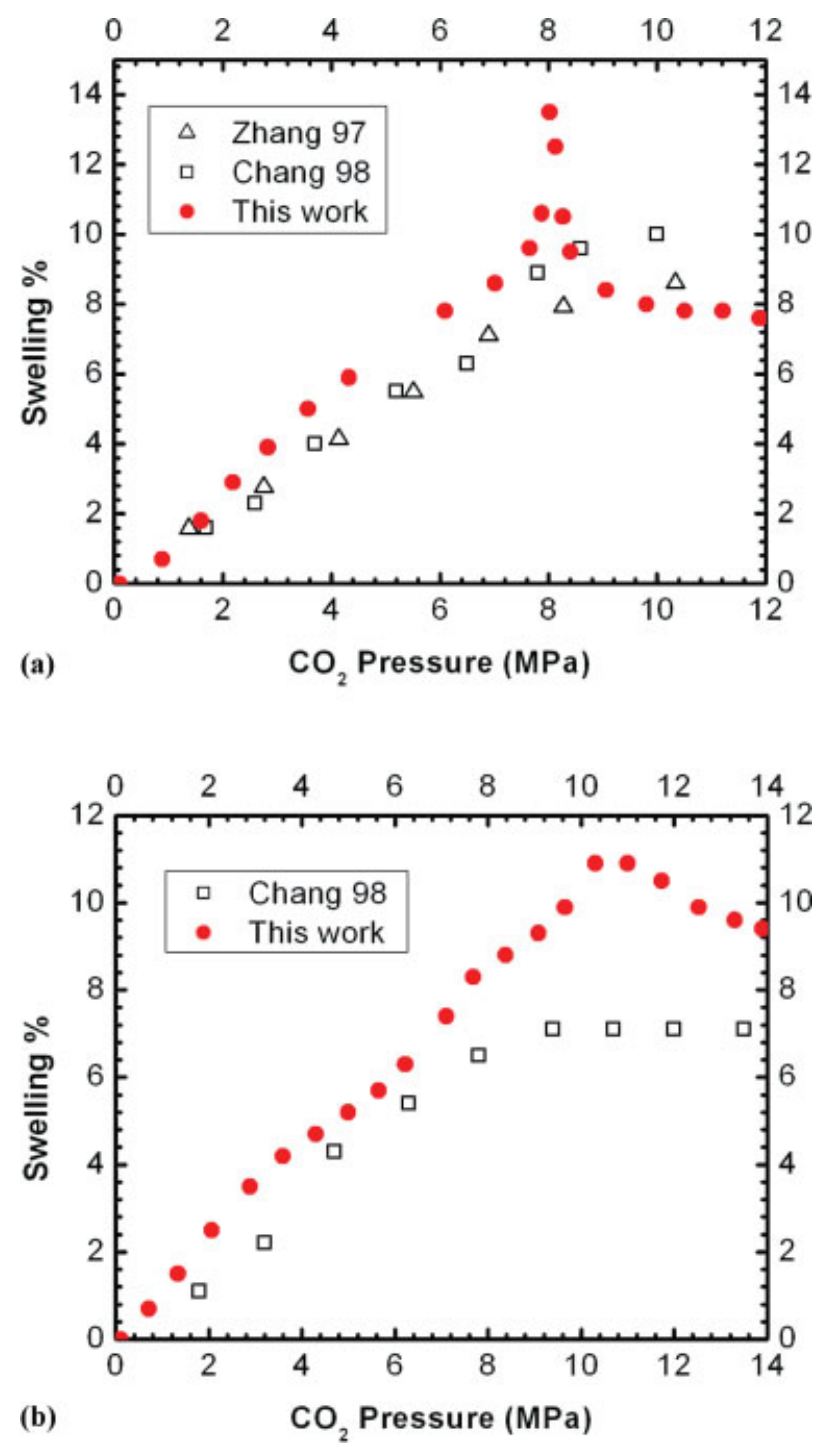

Figure 5. Comparison between our PS swelling isotherms at $35{ }^{\circ} \mathrm{C}$ (a) and $50{ }^{\circ} \mathrm{C}$ (b) with two reference works. [Color figure can be viewed in the online issue, which is available at www.interscience.wiley.com.]

interface), $\rho(z)$ is the local density of $\mathrm{CO}_{2}$ at distance $z$, and $\rho_{\text {bulk }}$ is the density of the bulk $\mathrm{CO}_{2}$. Because $\mathrm{CO}_{2}$ has low cohesive energy density, the interaction between $\mathrm{CO}_{2}$ and the surface may be expected to exceed the intermolecular attraction between pure $\mathrm{CO}_{2}$ molecules. Consistently, there is a difference between $\rho(z)$ and $\rho_{\text {bulk }}\left(\rho(z)>\rho_{\text {bulk }}\right)$, which leads to excesses of $\mathrm{CO}_{2}$ at the surface. However, if the anomalous swelling maximum is solely caused by this surface excess $\mathrm{CO}_{2}$ wetting layer, then $h_{\text {exc }}$ should be relatively independent on the initial film thickness. On the contrary, Table 2 indicates that the excess swelling thickness increases with increasing film thickness; clearly the observed excess swelling cannot be explained by the surface excess $\mathrm{CO}_{2}$ adsorption alone. A theoretical study by Wang and Sanchez ${ }^{56}$ determined the thickness of the surface excess $\mathrm{CO}_{2}$ adsorption layer to be around $2 \mathrm{~nm}$, which is much less than the observed $h_{\text {exc }}$. It turns out that this $2 \mathrm{~nm}$ thick surface excess $\mathrm{CO}_{2}$ layer is too thin to be accurately determined by ellipsometry, particularly with the small contrast. Attempts to add $\mathrm{CO}_{2}$ adsorption layer into the ellipsometry-fitting model only produce larger uncertainty and compromise the uniqueness of the fitting results.

Another factor that may contribute to anomalous swelling maximum is the excess $\mathrm{CO}_{2}$ adsorption on the substrate interface. Recent studies $^{54,55}$ on moisture adsorption in photoresist films have pointed out that the attractive interaction between water and hydrophilic surfaces causes an accumulation of water on the polymer/silicon interface. As a result, the swelling of photoresist films by moisture increases as decreasing film thickness. ${ }^{54,55}$ However, similar to the approach replying on surface $\mathrm{CO}_{2}$ wetting layer, attempts to explain the anomalous swelling maximum solely by $\mathrm{CO}_{2}$ adsorption on polymer/substrate interface cannot count the observed thickness dependence of $h_{\text {exc }}$.

The information discussed in the preceding paragraph (the thickness dependence) indicates that the anomalous swelling observed in polymer thin films cannot be solely due to interfaces. However, it is true that there would be excess $\mathrm{CO}_{2}$ in thin films compared to the bulk, because the entropy would lead to excess molecules at the interfaces. The comparison between PS films and bulk PS, Figure 5, reveals a slight swelling enhancement in thin films compared to the bulk. Moreover, the proportional maximum excess swelling, $\Delta_{\text {exc }}$, exhibits the following trend with the polymers from Table 2: PFOMA $<$ PS- $b$ PTHFOMA $<$ PS $<$ PEO. This trend is opposite to that of $S_{\max }$, which be understood by considering the fact that enhanced swelling at interfaces can be more dominant for polymer films that do not have a strong affinity with $\mathrm{CO}_{2}$.

For a more quantitative assessment of interfacial effects on the anomalous swelling maximum, a simple model is now proposed. Let's simply assume that a polymer film with thickness $h_{0}$ is composed, from top to bottom, of a $\mathrm{CO}_{2} /$ polymer interfacial layer $h_{0}^{\text {free }}$, a middle layer $h_{0}^{\mathrm{m}}$, and a polymer/substrate interfacial layer $h_{0}^{\text {sub }}$. By defin-

Journal of Polymer Science: Part B: Polymer Physics DOI 10.1002/polb 
Table 3. Summary of the Initial and Swollen Film Thicknesses at the Anomalous Maximum for Various Polymer Films in $\mathrm{CO}_{2}, 35{ }^{\circ} \mathrm{C}$

\begin{tabular}{|c|c|c|c|}
\hline Polymer & Data Source & $\begin{array}{c}\text { Initial Film } \\
\text { Thickness, } h_{0}(\mathrm{~nm})\end{array}$ & $\begin{array}{c}\text { Swollen Film } \\
\text { Thickness, } h(\mathrm{~nm})\end{array}$ \\
\hline \multirow[t]{4}{*}{ PFOMA } & This study & 109 & 242 \\
\hline & & 153 & 327 \\
\hline & & 179 & 435 \\
\hline & & 282 & 657 \\
\hline \multirow[t]{3}{*}{ PMMA } & Koga et al. ${ }^{35}$ & 9.8 & 14.2 \\
\hline & Sirard et al. ${ }^{25}$ & 88 & 108 \\
\hline & & 321 & 402 \\
\hline \multirow[t]{9}{*}{ PS } & This study & 128 & 145 \\
\hline & Koga et al. ${ }^{34}$ & 14 & 19 \\
\hline & & 17 & 22 \\
\hline & & 29 & 34 \\
\hline & & 60 & 66 \\
\hline & & 80 & 87 \\
\hline & & 107 & 117 \\
\hline & & 120 & 130 \\
\hline & & 44.5 & 51 \\
\hline \multirow[t]{6}{*}{$\mathrm{PB}$} & Koga et al. ${ }^{35}$ & 18 & 30 \\
\hline & & 32 & 51 \\
\hline & & 62 & 96 \\
\hline & & 99 & 153 \\
\hline & & 17 & 28 \\
\hline & & 31 & 49 \\
\hline
\end{tabular}

ing a swelling coefficient $(\alpha)$ for each layer, the initial thickness $\left(h_{0}\right)$ and the thickness after swelling (h) can be expressed by

$$
h_{0}=h_{0}^{\text {free }}+h_{0}^{\mathrm{m}}+h_{0}^{\mathrm{sub}},
$$

and

$$
\begin{aligned}
h & =h^{\text {free }}+h^{\mathrm{m}}+h^{\text {sub }} \\
& =\left(1+\alpha_{\text {free }}\right) h_{0}^{\text {free }}+\left(1+\alpha_{\mathrm{m}}\right) h_{0}^{\mathrm{m}}+\left(1+\alpha_{\mathrm{sub}}\right) h_{0}^{\text {sub }},
\end{aligned}
$$

Combining eqs 4 and 5 leads to

$$
h=A h_{0}+B,
$$

where $A=1+\alpha_{\mathrm{m}}$ and $B=\left(\alpha_{\text {free }}-\alpha_{\mathrm{m}}\right) h_{0}^{\text {free }}+\left(\alpha_{\text {sub }}\right.$ $\left.-\alpha_{\mathrm{m}}\right) h_{0}^{\mathrm{sub}}$.

Equation 6 indicates that at a certain pressure, a linear relationship exists between the swollen film thickness, $h$, and the initial film thickness, $h_{0}$. The slope of this linear relationship is related to the swelling coefficient of the middle layer $\left(\alpha_{\mathrm{m}}\right)$, while the intercept is dependent on the interfacial interactions $\left(\alpha_{\text {free }}\right.$ and $\left.\alpha_{\text {sub }}\right)$. Using the data in Table 3, a plot of $h$ and $h_{0}$ is made in Figure 6, which confirms that regardless of the polymer, the swollen film thickness at the anomalous maxima increases line-

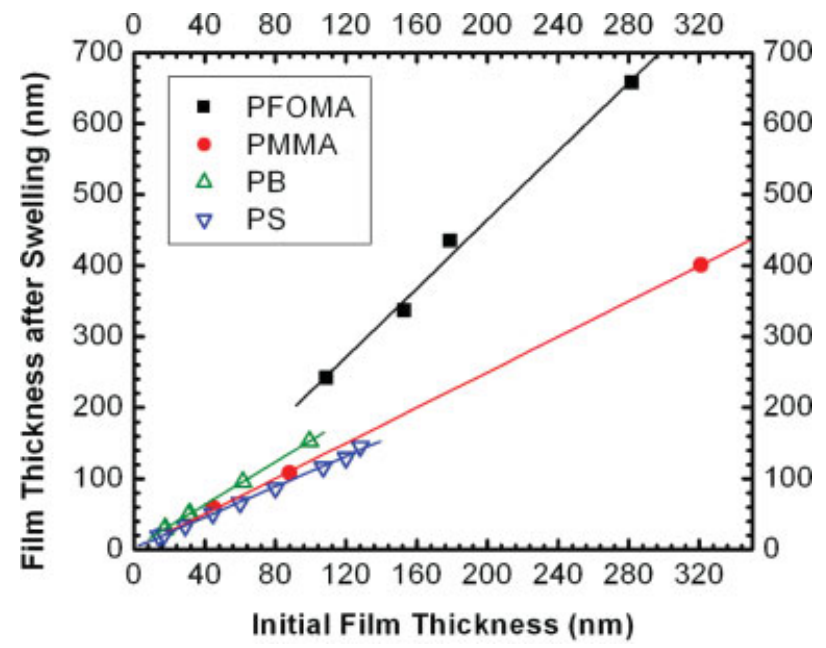

Figure 6. Film thicknesses for the swollen films at the anomalous maximum (7.9-8.0 $\mathrm{MPa})$ versus the initial film thicknesses for a variety of polymer films at $35{ }^{\circ} \mathrm{C}$. Linear lines are the fit from the experimental data. [Color figure can be viewed in the online issue, which is available at www.interscience.wiley. com.] 
Table 4. Summary of the Fitting Results Obtained from Figure 6

\begin{tabular}{lcccc}
\hline Polymer & $\begin{array}{c}\text { Slope } \\
\left(1+\alpha_{\mathrm{m}}\right)\end{array}$ & $\alpha_{\mathrm{m}}$ & Intercept & $\begin{array}{c}\text { Linearity } \\
R^{2}\end{array}$ \\
\hline PFOMA & 2.42 & 1.42 & -18.9 & 0.993 \\
PMMA & 1.25 & 0.25 & 0.602 & 0.999 \\
PS & 1.08 & 0.08 & 2.80 & 0.998 \\
PB & 1.51 & 0.51 & 3.35 & 0.999 \\
\hline
\end{tabular}

arly with the initial film thickness. The slopes and intercepts are summarized in Table 4, where the values of $\alpha_{\mathrm{m}}$ are also listed. PFOMA has higher $\alpha_{\mathrm{m}}$ than all other polymers, while PS processes the lowest $\alpha_{\mathrm{m}}$, which are expected to be based on the polymer/ $\mathrm{CO}_{2}$ interactions.

For internal consistency, the same analysis is applied to PFOMA films with various thicknesses at pressures different from the anomalous swelling maximum. Figure 7 shows fitted curves at 11 pressures distinct from the anomalous maximum. Figure 8 summarizes the results of $\alpha_{\mathrm{m}}$ from fitting the data in Figure 7. It is clear that $\alpha_{\mathrm{m}}$ increases with increasing $\mathrm{CO}_{2}$ pressure and exhibits a maximum at a pressure $\sim 8.0 \mathrm{MPa}$. This observed maximum in $\alpha_{\mathrm{m}}$ further confirms that the swelling of the middle layer also exhibits an anomalous behavior, which can be understood as follows. Because the phase stability of a binary mixture decreases with its compressi-

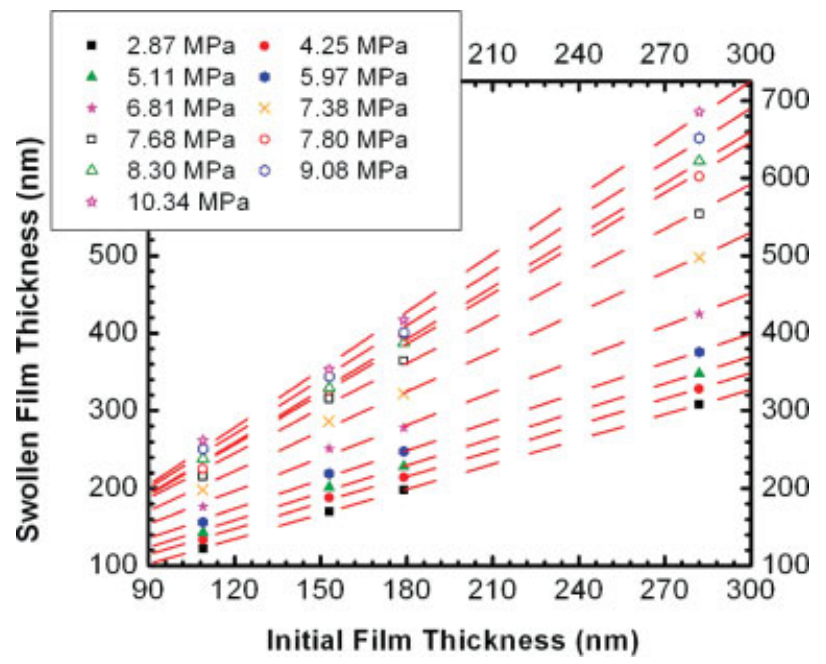

Figure 7. Film thicknesses for the swollen films versus the initial film thicknesses at pressure points other than the anomalous maximum for PFOMA films at $35{ }^{\circ} \mathrm{C}$. Linear lines are the fit from the experimental data.

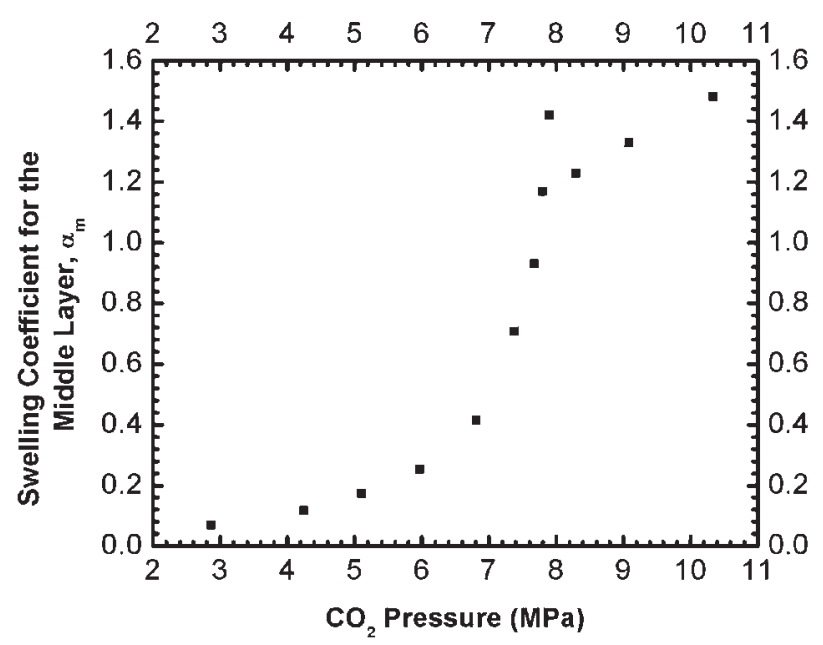

Figure 8. The swelling coefficients for the middle layer, $\alpha_{\mathrm{m}}$, versus $\mathrm{CO}_{2}$ pressure for PFOMA films at $35{ }^{\circ} \mathrm{C}$.

bility ${ }^{25,57}$ the solubility of $\mathrm{CO}_{2}$ in the polymer film decreases abruptly near the region where the compressibility of $\mathrm{CO}_{2}$ is at maximum. As a result, $\mathrm{CO}_{2}$-rich phase and polymer-rich phase may coexist in the film, leading to the observed anomalous maximum in $\alpha_{\mathrm{m}}$. Clearly, the anomalous maximum in $\alpha_{\mathrm{m}}$ further confirms that anomalous swelling is not solely due to the excess adsorption of $\mathrm{CO}_{2}$ at interfaces.

\section{CONCLUSIONS}

In situ spectroscopic ellipsometry was employed to examine the swelling of PFOMA, PS, PEO, and PS- $b$-PFOMA thin films in $\mathrm{Sc}-\mathrm{CO}_{2}$ with the goal to further understand the role of interfaces on anomalous swelling maximum. The experimental data of the dependence of anomalous maximum on polymers and film thicknesses from this study and several references ${ }^{25,34,35}$ can be rationalized by considering a three-layer model, which indicates that the anomalous swelling maximum cannot be solely explained by the excess adsorption of $\mathrm{CO}_{2}$ at interfaces $\left(\alpha_{\mathrm{free}}, \alpha_{\mathrm{sub}}\right)$. Instead, the swelling coefficient of the interior of the film $\left(\alpha_{\mathrm{m}}\right)$ plays an important role; it exhibits an anomalous swelling maximum, consistent with the behavior of the film. Clearly, this study further clarifies the role of interfacial interactions on the anomalous swelling maxima exhibited by polymer thin films exposed to compressible fluids.

Journal of Polymer Science: Part B: Polymer Physics 
This work is supported by the STC Program of the National Science Foundation under agreement CHE-9876674 and by the National Science Foundation under agreement DMR-0601890. Y. L. thanks Dr. R. Synowicki from J. A. Woollam Co. and Dr. A. M. Galvan for consulting on Ellipsometry modeling.

\section{REFERENCES AND NOTES}

1. Cooper, A. I. J Mater Chem 2000, 10, 207.

2. DeSimone, J. M. Science 2002, 297, 799.

3. Kazarian, S. G. Polym Sci Ser C 2000, 42, 78.

4. Yeo, S. D.; Erdogan, K. J Supercrit Fluids 2005, 34, 287.

5. Arceo, A.; Green, P. F. J Phys Chem B 2005, 109, 6958.

6. Li, Y.; Meli, L.; Lim, K. T.; Green, P. F.; Johnston, K. P. Macromolecules 2006, 39, 7044.

7. Li, Y.; Wang, X.; Sanchez, I. C.; Green, P. F.; Johnston, K. P. J Phys Chem B 2007, 111, 16.

8. Ramachandra Rao, V. S.; Gupta, R. R.; Russell, T. P.; Watkins, J. J. Macromolecules 2001, 34, 7923.

9. Meli, L.; Li, Y.; Lim, K. T.; Johnston, K. P.; Green, P. F. Unpublished work.

10. Pai, R. A.; Humayun, R.; Schulberg, M. T.; Sengupta, A.; Sun, J. N.; Watkins, J. J. Science 2004, 303, 507.

11. Zhang, X.; Pham, J. Q.; Ryza, N.; Green, P. F.; Johnston, K. P. J Vac Sci Technol B 2004, 22, 818.

12. Zhang, X.; Pham, J. Q.; Martinez, H. J.; Wolf, J.; Green, P. F.; Johnston, K. P. J Vac Sci Technol B 2003, 21, 2569.

13. O'Neill, A.; Watkins, J. J. MRS Bull 2005, 30, 967.

14. Keagy, J. A.; Zhang, X.; Johnston, K. P.; Busch, E.; Weber, F.; Wolf, P. J.; Rhoad, T. J Supercrit Fluids 2006, 39, 277.

15. Keagy, J. A.; Li, Y.; Green, P. F.; Johnston, K. P.; Weber, F.; Rhoad, J. T.; Busch, E. L.; Wolf, P. J. Supercrit Fluids 2007, in press.

16. Jones, C.; Zweber, A.; DeYoung, J.; McClain, J.; Carbonell, R.; DeSimone, J. Crit Rev Solid State Mater Sci 2004, 29, 97.

17. Gorman, B. P.; Orozco-Teran, R. A.; Zhang, Z.; Matz, P. D.; Mueller, W. D.; Reidy, R. F. J Vac Sci Technol B 2004, 22, 1210.

18. Xie, B.; Muscat, A. J Microelectron Eng 2004, 76, 52.

19. Cao, T.; Johnston, K. P.; Webber, S. E. Macromolecules 2005, 38, 1335.

20. Meli, L.; Pham, J. Q.; Johnston, K. P.; Green, P. F. Phys Rev E 2004, 69, 051601.

21. Pham, J. Q.; Johnston, K. P.; Green, P. F. J Phys Chem B 2004, 108, 3457.

22. Pham, J. Q.; Sirard, S. M.; Johnston, K. P.; Green, P. F. Phys Rev Lett 2003, 91, 175503.

Journal of Polymer Science: Part B: Polymer Physics DOI 10.1002/polb
23. Sirard, S. M.; Green, P. F.; Johnston, K. P. J Phys Chem B 2001, 105, 766.

24. Sirard, S. M.; Gupta, R. R.; Russell, T. P.; Watkins, J. J.; Green, P. F.; Johnston, K. P. Macromolecules 2003, 36, 3365.

25. Sirard, S. M.; Ziegler, K. J.; Sanchez, I. C.; Green, P. F.; Johnston, K. P. Macromolecules 2002, 35 1928.

26. Findenegg, G. H., In Fundamentals of Adsorption; Myers, A. L.; Belfort, G., Eds.; Engineering Foundation: New York, 1984, p 207.

27. Strubinger, J. R.; Song, H.; Parcher, J. F. Anal Chem 1991, 63, 98.

28. Strubinger, J. R.; Parcher, J. F. Anal Chem 1989, $61,951$.

29. Zhou, L.; Bai, S.; Su, W.; Yang, J.; Zhou, Y. Langmuir 2003, 19, 2683.

30. Giovanni, O. D.; Dorfler, W.; Mazzotti, M.; Morbidelli, M. Langmuir 2001, 17, 4316.

31. Gao, W.; Butler, D.; Tomasko, D. L. Langmuir 2004, 20, 8083.

32. Chen, J. H.; Wong, D. S. H.; Tan, C. S.; Subramanian, R.; Lira, C. T.; Orth, M. Ind Eng Chem Res 1997, 36, 2808.

33. Kiselev, S. B.; Ely, J. F.; Belyakov, M. Y. J Chem Phys 2000, 112, 3370.

34. Koga, T.; Seo, Y. S.; Zhang, Y.; Shin, K.; Kusano, K.; Nishikawa, K.; Rafailovich, M. H.; Sokolov, J. C.; Chu, B.; Peiffer, D.; Occhiogrosso, R.; Satija, S. K. Phys Rev Lett 2002, 89, 125506.

35. Koga, T.; Seo, Y. S.; Shin, K.; Zhang, Y.; Rafailovich, M. H.; Sokolov, J. C.; Chu, B.; Satija, S. K. Macromolecules 2003, 36, 5236.

36. Koga, T.; Akashige, E.; Reinstein, A.; Bronner, M.; Seo, Y. S.; Shin, K.; Rafailovich, M. H.; Sokolov, J. C.; Chu, B.; Satija, S. K. Physica B 2005, 357, 73.

37. Carbonell, R. G.; Carla, V.; Hussain, Y.; Doghieri, F. In Proceedings of Eighth Conference on Supercritical Fluids and Their Applications, Ischia, Italy, 28-31 May 2006.

38. Koga, T.; Seo, Y. S.; Hu, X.; Shin, K.; Zhang, Y.; Rafailovich, M. H.; Sokolov, J. C.; Chu, B.; Satija, S. K. Europhys Lett 2002, 60, 559.

39. Koga, T.; Ji, Y.; Seo, Y. S.; Gordon, C.; Qu, F.; Rafailovich, M. H.; Sokolov, J. C.; Satija, S. K. J Polym Sci B: Polym Phys 2004, 42, 3282.

40. Abramowitz, H.; Shah, P. S.; Green, P. F.; Johnston, K. P. Macromolecules 2004, 37, 73167324.

41. Sirard, S. M.; Castellanos, H.; Hwang, H. S.; Lim, K. T.; Johnston, K. P. Ind Eng Chem Res 2004, 43,525 .

42. Tompkins, H. G.; McGahan, W. A. Spectroscopic Ellipsometry and Reflectometry; Wiley: New York, 1999.

43. Pham, V. Q.; Rao, N.; Ober, C. K. J Supercrit Fluids 2004, 31, 323. 
44. Chang, S. H.; Park, S. C.; Shim, J. J. J Supercrit Fluids 1998, 13, 113.

45. Reiter, G.; Sommer, J. U. Phys Rev Lett 1998, 80, 3771.

46. Reiter, G.; Castelein, G.; Sommer, J. U. Phys Rev Lett 2001, 87, 226101.

47. Reiter, G. J Polym Sci B: Polym Phys 2003, 41, 1869.

48. Madsen, L. A. Macromolecules 2006, 39, 1483.

49. Lambert, S. M.; Paulaitis, M. E. J Supercrit Fluids 1991, 4, 15.

50. Beckman, E.; Porter, R. S. J Polym Sci B: Polym Phys 1987, 25, 1511.

51. Weidner, E.; Wiesmet, V.; Knez, Z.; Skerget, M. J Supercrit Fluids 1997, 10, 139.
52. Wissinger, R. G.; Paulaitis, M. E. J Polym Sci B: Polym Phys 1987, 25, 2497.

53. Zhang, Y.; Gangwani, K. K.; Lemert, R. M. J Supercrit Fluids 1997, 11, 115.

54. Beck Tan, N. C.; Wu, W. L.; Wallace, W. E.; Davis, G. T. J Polym Sci B: Polym Phys 1998, $36,155$.

55. Vogt, B. D.; Soles, C. L.; Jones, R. L.; Wang, C. Y.; Lin, E. K.; Wu, W. L.; Satija, S. K. Langmuir 2004, 20, 5285.

56. Wang, X.; Sanchez, I. C. Langmuir 2006, 22, 9251.

57. Sanchez, I. C.; Stone, M. T. In Polymer Blends; Paul, D. R.; Bucknall, C. B., Eds.; Wiley: New York, 2000. 